\title{
BMJ Open Development and validation of a clinical rule for recognition of early inflammatory arthritis
}

\author{
Robin M ten Brinck, ${ }^{1}$ Bastiaan T van Dijk, ${ }^{1}$ Hanna W van Steenbergen, ${ }^{1}$ \\ Saskia le Cessie, ${ }^{2}$ Mattijs E Numans, ${ }^{3}$ Samantha L Hider, ${ }^{4,5}$ Christian Mallen, ${ }^{4}$ \\ Annette van der Helm-van Mil ${ }^{1}$
}

To cite: ten Brinck RM, van Dijk BT, van Steenbergen HW, et al. Development and validation of a clinical rule for recognition of early inflammatory arthritis. BMJ Open 2018;8:e023552. doi:10.1136/ bmjopen-2018-023552

- Prepublication history and additional material for this paper are available online. To view these files, please visit the journal online (http://dx.doi org/10.1136/bmjopen-2018023552).

$\mathrm{RMB}$ and BTD contributed equally.

Received 11 April 2018 Revised 8 August 2018 Accepted 3 October 2018

Check for updates

(C) Author(s) (or their employer(s)) 2018. Re-use permitted under CC BY-NC. No commercial re-use. See rights and permissions. Published by BMJ.

For numbered affiliations see end of article.

Correspondence to Robin M ten Brinck; r.m.ten_brinck@lumc.nl

\section{ABSTRACT}

Objectives National and international guidelines recommend prompt referral of patients presenting with inflammatory arthritis (IA), but general practitioners (GPs) feel uncertain in their proficiency to detect synovitis through joint examination, the method of choice to identify IA. Our objective was to develop and validate a rule composed of clinical characteristics to assist GPs and other physicians in identifying IA when in doubt. Design Split-sample derivation and validation study. Setting The Leiden Early Arthritis Recognition Clinic (EARC), a screening clinic for patients in whom GPs suspected but were unsure of the presence of IA. Participants 1288 consecutive patients visiting the EARC Primary and secondary outcome measures Associations of clinical characteristics with presence of IA were determined using logistic regression in 644 patients, while validating the results in the other 644 patients (split-sample validation). To facilitate application in clinical practice, a simplified rule (with scores ranging from 0 to 7.5) was derived and validated. Results IA was identified by a rheumatologist in $41 \%$ of patients. In univariable analysis, male gender, age $\geq 60$ years, symptom duration $<6$ weeks, morning stiffness $>60$ min, a low number of painful joints (1-3 joints), presence of patient-reported joint swelling and difficulty with making a fist were associated with IA in the derivation data set. Using multivariable analysis, a simplified rule consisting of these seven items was derived and validated, yielding an area under the receiver operator characteristic curve (AUC) of 0.74 (95\% Cl 0.70 to 0.78 ) in the derivation data set. Validation yielded an AUC of $0.71(95 \% \mathrm{Cl} 0.67$ to 0.75). Finally, the model was repeated to study predicted probabilities with a lower prevalence of inflammatory arthritis to simulate performance in primary care settings. Conclusions Our rule, composed of clinical parameters, had reasonable discriminative ability for IA and could assist physicians in decision-making in patients with suspected IA, increasing appropriateness of healthcare utilisation.

\section{BACKGROUND}

Early initiation of disease modifying antirheumatic drugs is strongly associated with improved outcomes of rheumatoid arthritis (RA). ${ }^{1}$ National and international guidelines

\section{Strengths and limitations of this study}

- A clinical rule could help to select patients to refer for additional investigations (laboratory or imaging) or to secondary care. This could promote early identification of inflammatory arthritis and increase appropriateness of healthcare utilisation.

- Data were collected prospectively in a population of patients in which general practitioners had doubt on the presence of inflammatory arthritis.

- The main limitation is that data were not collected in primary care itself, but in a setting intermediary between primary and secondary care. Further external validation in general practitioner settings is therefore required.

attempt to facilitate this by emphasising prompt referral of patients presenting with inflammatory arthritis (IA) to a rheumatologist. The European League Against Rheumatism taskforce for the management of early IA recommends referral within 6 weeks of onset of symptoms, ${ }^{2}$ while in the UK, the National Institute for Health and Care Excellence (NICE) guidelines advises referral to a rheumatologist in patients with new, persistent (>3-4 weeks) synovitis within 3 working days. ${ }^{3}$ However, it was demonstrated that this referral timeline is achieved in only $17 \%$ of patients. ${ }^{4}$ On average, patients with RA are seen four (and sometimes more than eight) times by general practitioners (GPs) before they refer to secondary care, ${ }^{5-8}$ which may reflect the difficulty of differentiating patients with early IA from patients with other types of common musculoskeletal symptoms. A recent qualitative study revealed that GPs acknowledge the importance of early detection and referral, but feel uncertain in their proficiency to detect synovitis through joint examination, the method of choice to identify IA. ${ }^{29}$ As a consequence, the referral to a rheumatologist 
may be delayed, which contributes to overall treatment delay in early RA, as observed in Europe..$^{1011}$

This is further complicated by the high incidence of consultations for various common musculoskeletal symptoms and the low incidence of early IA in primary care. ${ }^{12}$ The consultation prevalence of any musculoskeletal symptom in primary care in the UK approximates 2405 per 10000 per year, ${ }^{13}$ making it the most common organ system consulted for at GP practices. ${ }^{12-14}$ Although musculoskeletal symptoms are common, GPs suspect IA (based on pattern recognition) in only a very small minority of patients. ${ }^{5}$ In these patients, GPs often lack confidence in joint assessment for synovitis.

To support early detection, several initiatives have been developed, including triage systems. The best studied triage system (the Early Inflammatory Arthritis Questionnaire) was developed and validated for patients attending secondary and tertiary care. ${ }^{15-17}$ Furthermore, several referral guidelines for $\mathrm{GPs}^{6}{ }^{6-22}$ and public awareness campaigns have been developed, for instance, one attempting to simplify pattern recognition to the 'S-Factor': Stiffness, Swelling, Squeezing. However, none of these initiatives were designed using primary care data, and all assume that GPs can differentiate between the presence and absence of joint swelling, ${ }^{6}{ }^{18-20}$ which continues to be a barrier to the early detection of IA.

Altogether, there is a contradiction with the need to refer as quickly as possible while evidence who must be referred or, in line with this, in whom additional investigations are appropriate is lacking. To solve the issue, we have developed and validated a rule composed of clinical characteristics, by taking advantage of data from a setting intermediate between primary and secondary care. This intermediate setting of an the Early Arthritis Recognition Clinic (EARC) was a local solution to promote early referrals and is not easily implementable in other regions. The clinical rule derived from these data, however, is easy to apply and may assist in the decision-making process in patients with musculoskeletal symptoms with suspected IA at other places, in order to promote early identification of IA.

\section{METHODS}

\section{Study population}

To promote early recognition of early IA, EARC was initiated in September 2010 in Leiden, the Netherlands. The outpatient clinic of the Department of Rheumatology of the Leiden University Medical Centre (LUMC) is the only referral centre in a healthcare region of $\sim 400000$ people. GPs were instructed to refer patients to EARC in whom they were unsure about the presence of IA (instead of a 'wait-and-see' approach or performing additional tests). EARC system has reduced referral delay from 8 to 2 weeks, and improved early identification of IA. ${ }^{1123}$ To emphasise the importance of early identification of IA and aiming to inform on the purpose of $\mathrm{EA} R \mathrm{C}$, a region-wide educational campaign was conducted among regional GPs.
In addition to (and distinct from) EARC, the LUMC also has an Early Arthritis Clinic (EAC). EAC was established in 1993 to include and follow patients with early arthritis and to offer the possibility of rapid access to rheumatology care, usually within a week of referral. To differentiate between the clinics, GPs were instructed to refer to EAC if there was a clear synovitis or very high suspicion of IA (ie, to continue as they had before, since there was no benefit for such patients to go to EARC first) and to refer to $\mathrm{EARC}$ when in doubt about the presence of IA (ie, to not 'wait-and-see' or order additional tests). Thus, patients included in this study represent the difficult group in whom GPs were uncertain of the presence of suspected IA; patients with a very high degree of suspicion were referred directly to EAC.

EARC screening clinic was held twice a week between 2010 and 2014 and once a week from 2014 onwards. After GP referral, patients can visit EARC without an appointment. All patients that visited EARC between 2010 and September 2015 were studied.

\section{Data collection}

At EARC, patients completed a short questionnaire about their joint symptoms, after which they were seen by an experienced rheumatologist (AvdHvM or other senior

Table 1 Characteristics of patients visiting the Early Arthritis Recognition Clinic

\begin{tabular}{llll}
\hline & \multicolumn{3}{l}{ Derivation Validation } \\
$(\mathbf{n = 6 4 4 )}$ & $\mathbf{( n = 6 4 4 )}$ & P values $^{*}$ \\
\hline Male, $\mathrm{n}(\%)$ & $190(30)$ & $198(31)$ & 0.62 \\
\hline Age in years, mean \pm SD & $52 \pm 16$ & $51 \pm 17$ & 0.27 \\
\hline $\begin{array}{l}\text { Symptom duration in } \\
\text { weeks, median (IQR) }\end{array}$ & $10(3-45)$ & $12(4-45)$ & 0.18 \\
\hline $\begin{array}{l}\text { Acute onset of } \\
\text { symptomst, } \mathrm{n}(\%)\end{array}$ & $252(39)$ & $238(37)$ & 0.45 \\
$\begin{array}{l}\text { Symptoms worst in the } \\
\text { early morning, } \mathrm{n}(\%)\end{array}$ & $372(58)$ & $351(55)$ & 0.10 \\
$\begin{array}{l}\text { Morning stiffness in } \\
\text { minutes, median (IQR) }\end{array}$ & $10(0-30)$ & $10(0-30)$ & 0.33 \\
$\begin{array}{l}\text { Number of painful joints, } \\
\text { median (IQR) }\end{array}$ & $7(2-15)$ & $6(3-15)$ & 0.69 \\
$\begin{array}{l}\text { Number of patient- } \\
\text { reported swollen joints, } \\
\text { median (IQR) }\end{array}$ & $2(1-5)$ & $2(1-5)$ & 0.19 \\
$\begin{array}{l}\text { Difficulty with making a } \\
\text { fist, } \mathrm{n} \text { (\%) }\end{array}$ & $329(51)$ & $301(47)$ & 0.06 \\
$\begin{array}{l}\text { Arthritis present at } \\
\text { joint examination } \\
\text { by experienced } \\
\text { rheumatologist, } \mathrm{n}(\%)\end{array}$ & $271(42)$ & $252(39)$ & 0.28 \\
\hline
\end{tabular}

*Unpaired t-tests, $\chi^{2}$ tests and Mann-Whitney $U$ tests were used as appropriate.

†Patients were asked to define onset of symptoms; either acute onset of symptoms or gradual onset of symptoms, see online supplementary appendix S1. 
rheumatologists) who performed a full 66-joint examination. If synovitis was determined by physical examination, patients were fast-tracked to visit EAC within 1 week for further evaluation and treatment. Patients without IA were discharged to primary care. The questionnaire completed by patients, provided in online supplementary appendix S1, contained questions on age, gender, date of symptom onset, date of first visit to GP, presence of a (sub)acute symptom onset (vs a gradual symptom-onset), morning stiffness (duration in minutes), which part of the day symptoms were worst and whether they had difficulty with making a fist. Patients were asked to indicate on a 52-joint mannequin which joints were painful and which joints they considered to be swollen. IA, defined as synovitis confirmed by the rheumatologist at physical examination, was used as outcome.

Collected data were anonymised and entered in a research database at chronological order of visiting EARC.

\section{Derivation and validation of the model}

We used half of the data set for derivation and the other half for validation of results (split-sample validation). To prevent bias by (unknown) effects of inclusion period, patients with odd ID numbers (1, 3, etc) were included in the derivation data set and those with even ID numbers $(2,4$, etc) were used for validation.

To prevent exclusion of patients with one or more missing variables, we imputed missing values using chained equations ${ }^{24}$; frequencies of missing variables are presented in online supplementary appendix S2. The variables 'difficulty with making a fist' and 'self-reported joint swelling' were most frequently missing as these were added to the questionnaire after 1 April 2012, thus absence of these data was considered to occur completely at random.

We conducted logistic regression analysis modelling with presence of IA (defined as rheumatologist-confirmed synovitis on physical examination) as dependent variable. Continuous variables were categorised using clinically relevant cut-offs: age: $<40 / 40-59.9 / \geq 60$ years; duration of symptoms: $<6 / 6-11 / 12-51.9 / \geq 52$ weeks; duration of morning stiffness: $\leq 60 />60 \mathrm{~min}$; number of painful joints: $0 / 1-3 / 4-10 / \geq 11$; number of swollen joints: $0 / 1-3 / 4-$ $10 / \geq 11$. We performed univariable logistic regression to evaluate associations between dependent variables and

Table 2 Univariable logistic regression in the derivation data set with presence of synovitis on joint examination as outcome

\begin{tabular}{|c|c|c|c|}
\hline & Arthritis $(n=271)$ & No arthritis $(n=373)$ & OR $(95 \% \mathrm{Cl})$ \\
\hline Male, $n(\%)$ & $104(38)$ & $86(23)$ & 2.1 (1.5 to 2.9$)$ \\
\hline \multicolumn{4}{|l|}{ Age, n (\%) } \\
\hline$<40$ & $49(18)$ & $104(28)$ & (ref) \\
\hline $40-59.9$ & $109(40)$ & $172(46)$ & $1.3(0.89$ to 2.0$)$ \\
\hline$\geq 60$ & $113(42)$ & $97(26)$ & 2.5 (1.6 to 3.8$)$ \\
\hline \multicolumn{4}{|l|}{ Symptom duration in weeks, $\mathrm{n}(\%)$} \\
\hline$<6$ & $124(46)$ & $103(28)$ & 3.8 (2.4 to 5.9$)$ \\
\hline $6-11$ & $38(14)$ & $62(17)$ & $1.9(1.1$ to 3.9$)$ \\
\hline $12-51.9$ & $66(24)$ & $75(20)$ & 2.7 (1.7 to 4.5$)$ \\
\hline$\geq 52$ & $43(16)$ & $132(36)$ & (ref) \\
\hline Acute onset of symptoms *, $n(\%)$ & $122(45)$ & $131(35)$ & $1.5(1.1$ to 2.1$)$ \\
\hline Symptoms worst in early morning, $\mathrm{n}(\%)$ & $158(58)$ & $214(57)$ & $1.1(0.69$ to 1.6$)$ \\
\hline Morning stiffness > $60 \mathrm{~min}, \mathrm{n}(\%)$ & $45(17)$ & $40(11)$ & 1.7 (1.03 to 2.7$)$ \\
\hline \multicolumn{4}{|l|}{ Number of painful joints, $\mathrm{n}(\%)$} \\
\hline 0 & $1(0)$ & $10(3)$ & (ref) \\
\hline $1-3$ & $110(41)$ & $82(22)$ & $13.2(1.7$ to 105.5$)$ \\
\hline $4-10$ & $76(28)$ & $123(33)$ & $6.1(0.77$ to 49.0$)$ \\
\hline$\geq 11$ & $84(31)$ & $158(42)$ & $5.2(0.65$ to 41.3$)$ \\
\hline \multicolumn{4}{|c|}{ Number of patient-reported swollen joints, $\mathrm{n}(\%)$} \\
\hline 0 & $18(7)$ & $71(19)$ & (ref) \\
\hline $1-3$ & $115(42)$ & $119(32)$ & 3.7 (2.0 to 6.9 ) \\
\hline $4-10$ & $87(32)$ & $115(31)$ & $2.9(1.5$ to 5.5$)$ \\
\hline$\geq 11$ & $51(19)$ & $68(18)$ & 2.9 (1.4 to 5.9$)$ \\
\hline Difficulty with making a fist, $\mathrm{n}(\%)$ & $156(58)$ & $172(46)$ & $1.6(1.1$ to 2.4$)$ \\
\hline
\end{tabular}

*Patients were asked to define onset of symptoms; either acute onset of symptoms or gradual onset of symptoms, see online supplementary appendix S1. 
presence of IA. Variables with $\mathrm{p}$ values $<0.05$ in univariable analyses were entered in multivariable regression analyses (enter model) to obtain a model with a small number of variables. If several categories within a variable had similar regression coefficients in multivariable modelling, we pooled these categories and repeated the analysis. In subanalysis, we also performed a multivariable logistic regression model with the pooled categories using backward selection.

To obtain a simplified rule applicable in daily care, we rounded the regression coefficients of the final multivariable logistic regression model to the nearest 0.5 (irrespective of $p$ value). This resulted in an easily calculable risk score. For each value of the risk score, we determined test characteristics (ie, sensitivity and specificity) and predicted probabilities of the presence of inflammatory arthritis.

We evaluated the overall discriminative ability of the models using the area under the receiver operating characteristic curve (AUC). The model's calibration was assessed by generating a calibration plot to measure goodness of fit, where the data were partitioned in 10 equally sized groups based on the predicted probabilities using the final fitted multivariable model. In each group, the average predicted probability on current IA was compared with the observed prevalence, both in the derivation and validation data set. Additionally, the Hosmer-Lemeshow statistic was calculated.

To estimate performance of our simplified rule in a setting with a different prevalence of IA (eg, primary care), a simulation was performed. Accurate data on prevalence of IA in GP practices are lacking, and therefore an estimation was made based on previous literature. One study revealed that $27 \%$ assigned with the International Classification of Primary Care-1 code for suspected IA in their medical record had confirmed RA $(n=38)$, polyarthritis $(n=5)$ or oligoarthritis $(n=8)$ following rheumatologist's assessment. Another study among GPs found that $18 \%$ of patients with suspected IA was referred; though data on rheumatologists' diagnoses were not provided. ${ }^{25}$

Table 3 Multivariable logistic regression analyses with synovitis on joint examination as outcome

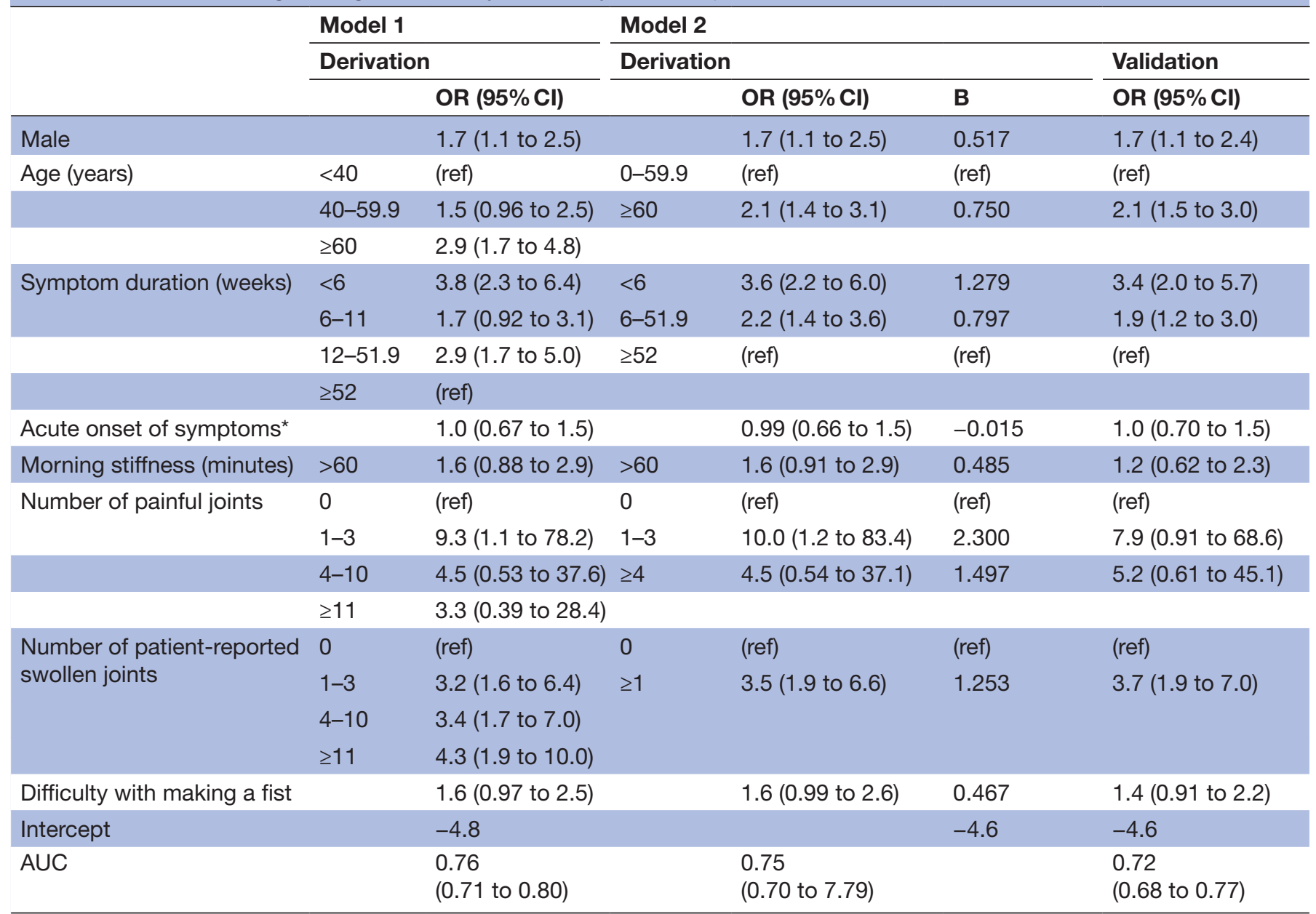

Model 1 includes categories of clinically applicable cut-offs; if within variables, several categories had similar regression coefficients, categories were pooled (model 2).

*Patients were asked to define onset of symptoms; either acute onset of symptoms or gradual onset of symptoms, see online supplementary appendix S1. Variables with $p$ values $<0.05$ in univariable analysis in the derivation set were entered in multivariable regression analyses. AUC, area under the receiver operating characteristic curve; B, beta. 
Guided by these scarce data obtained in GP practices, performance of the model was simulated with an estimated prevalence of $20 \% .{ }^{5}$ The intercept of the regression model was adjusted as described in King et $a l^{26} 27$ and we plotted average estimated predicted probabilities against the regression and simplified risk score.

Statistical analyses were performed using Statistical Package for the Social Sciences (SPSS, V.23.0). P values $<0.05$ were considered significant.

\section{Patient involvement}

Patient research partners agreed with the pathway of care at EARC. They also provided feedback on the questionnaire, which was expanded in 2012 with two questions.

\section{RESULTS}

\section{Patients}

One thousand two hundred and eighty-eight patients in whom GPs were unsure about the presence of IA visited EARC between 2010 and 2015; of these, $41 \%$ had synovitis at joint examination. The frequency of inflammatory arthritis was stable throughout the study years (see online supplementary appendix S3). Baseline characteristics of patients in both derivation and validation data set are presented in table 1 .

\section{Model derivation}

In univariable analyses, male gender, age $\geq 60$ years, symptom duration of $<6$ weeks, an acute onset of symptoms, morning stiffness $>60 \mathrm{~min}$, a low number of painful joints (1-3 joints), presence of patient-reported joint swelling (1-3 joints) and difficulty with making a fist were associated with the presence of IA in the derivation data set (table 2). 'Symptoms worst in the early morning' was not associated with IA and therefore not included in multivariable analysis. Two multivariable models were created with categorised variables; first, a model with categories similar to the univariable analysis (table 3, model 1), and second a model pooling categories per variable with similar regression coefficients (table 3, model 2). Performing this second model in the derivation data set revealed that male gender, age $\geq 60$ years, symptom duration of $<6$ weeks, a low number of painful joints (1-3 joints), and presence of patient-reported joint swelling were independently associated with the presence of IA (table 3). The AUC of model 2 was 0.75 (95\% CI 0.70 to 0.79 ) in the derivation dataset. In subanalysis, model 2 was repeated with a backward selection procedure, showing similar regression coefficients (see online supplementary appendix S4).

\section{Generation of a simplified rule}

In order to facilitate usage in routine clinical practice, a simplified model was generated (see online supplementary appendix S5). The obtained regression coefficient of acute onset of symptoms in multivariable modelling was -0.015 , yielding 0 points. Also after exclusion of this variable, the regression coefficients of the other seven variables in the model did not change yielding similar points. This resulted in a simplified rule consisting of seven scored items and a total score ranging from 0 to 7.5 with corresponding predicted risks (figure 1). Risks of IA predicted by the model as a function of the regression score (ie, the sum of the regression coefficients times the value of the corresponding covariates) are presented in figure 2A; as shown, simplification did not majorly affect the predicted risks. The calibration plot shows that predicted probabilities correlated well with the observed proportions of patients with IA (see online supplementary appendix S6). The Hosmer-Lemeshow test for the derivation data set yielded a $\mathrm{p}$ value of 0.36 . If cut-offs are required and a highly sensitive approach is preferred ( $>90 \%$ sensitivity), this is obtained by a cut-off score of $\geq 4$. When a highly specific approach is preferred ( $>90 \%$ specificity), this

\begin{tabular}{|c|c|c|}
\hline Male gender & 0.5 point & $\ldots .$. \\
\hline Age $\geq 60$ years & 0.5 point & ..... \\
\hline \multicolumn{3}{|l|}{ Symptom duration } \\
\hline$<6$ weeks & 1.5 points & ..... \\
\hline $6-51.9$ weeks & 1 point & ..... \\
\hline \multicolumn{3}{|l|}{ Morning stiffness } \\
\hline$>60 \min$ & 0.5 point & $\cdots .$. \\
\hline \multicolumn{3}{|c|}{ Number of patient-reported painful joints } \\
\hline $1-3$ & 2.5 points & ...... \\
\hline$\geq 4$ & 1.5 points & $\cdots \cdot$ \\
\hline \multicolumn{3}{|l|}{ Patient-reported joint swelling } \\
\hline$\geq 1$ & 1.5 points & ..... \\
\hline Difficulty with making a fist & 0.5 point & ..... \\
\hline & Total score & \\
\hline
\end{tabular}
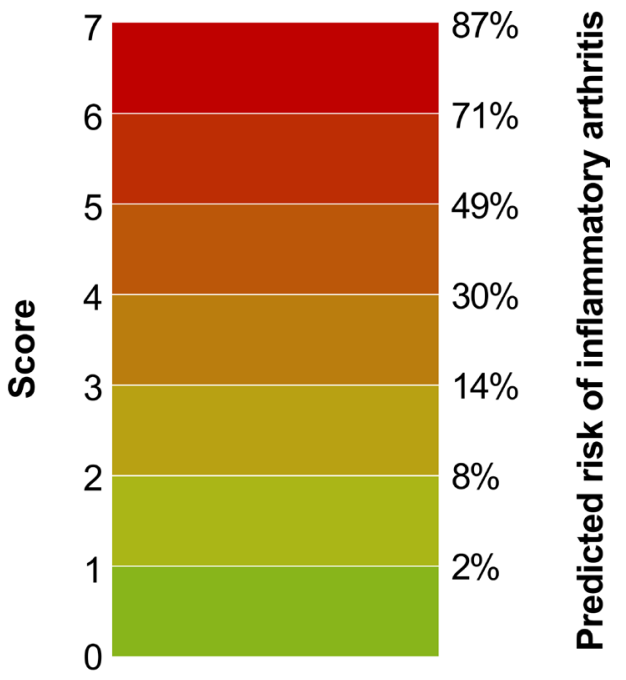

Figure 1 The Clinical Arthritis RulE and corresponding predicted risks of the presence of inflammatory arthritis per score. Observed risks of current inflammatory arthritis were obtained by calculating the proportion of patients with a positive outcome (rheumatologist-confirmed synovitis) for each value of the risk score in the derivation data set. 
A. Probability of arthrits with prevalence of arthritis of $41 \%$

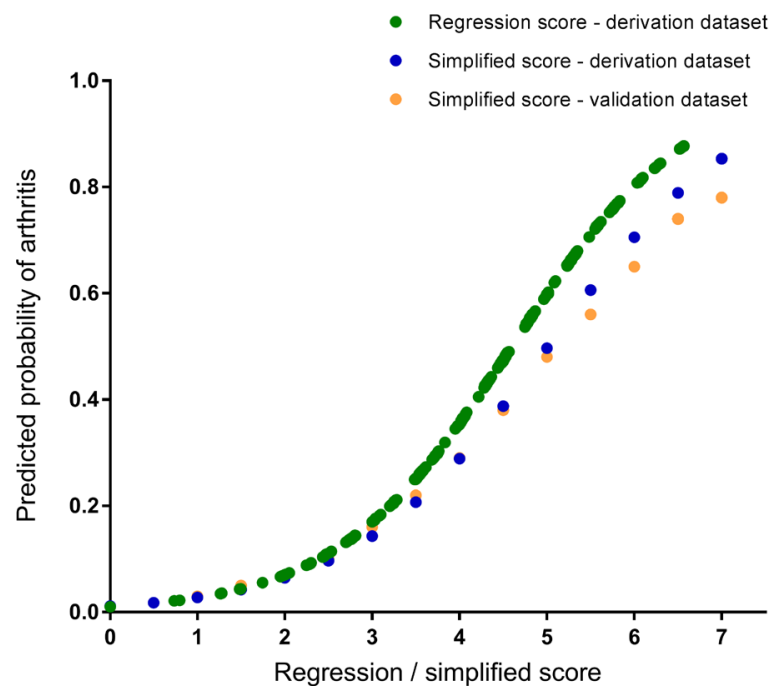

B. Simulation; prevalence of arthritis set to $20 \%$

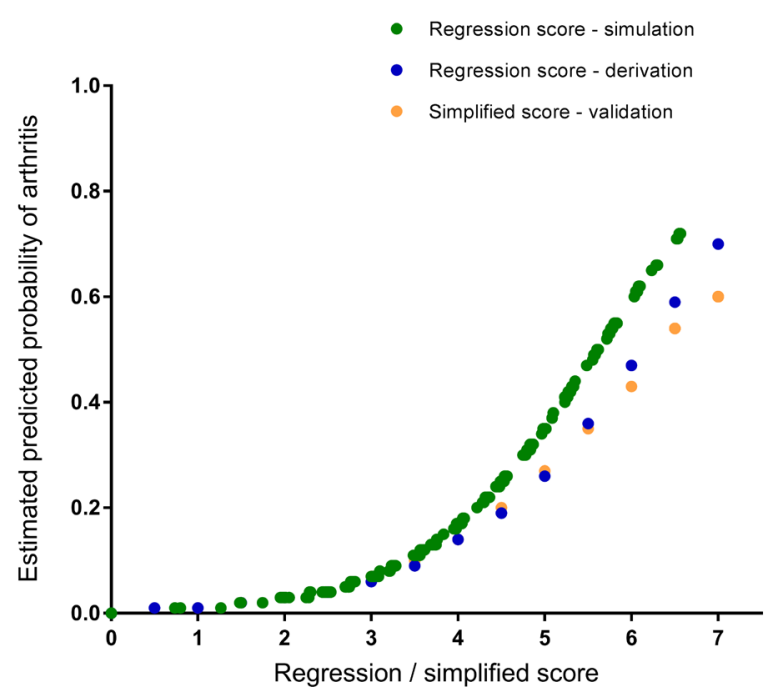

Figure 2 The Clinical Arthritis RulE and presentation of the predicted probabilities of the presence of current inflammatory arthritis based on the regression model, and the simplified score as observed in the derivation and validation data sets $(\mathrm{A})$, and estimated predicted probabilities in a simulation with a pretest probability (ie, prevalence) of inflammatory arthritis of $20 \%$ (B). Predicted probabilities of the final multivariable logistic regression model, fitted in the derivation set as function of the regression score (ie, the sum of the regression coefficients times the value of the corresponding covariates (green line)). Furthermore, for each value of the simplified score, the mean predicted probability is plotted in the derivation and validation dataset (blue and orange dots).

is obtained by a cut-off score of $\geq 6$. Test characteristics for all cut-off points are presented in online supplementary appendix S7. The AUC of the simplified score, measuring discrimination, was 0.74 (95\% CI 0.70 to 0.78 ; see online supplementary appendix $\mathrm{S} 8$ ).

\section{Validation}

The final multivariable model (model 2) was applied in the validation data set, revealing similar results (table 3 ). The AUC was 0.72 (95\% CI 0.68 to 0.77 ). Figure 2A shows the predicted probabilities of the simplified rule are almost similar to those obtained in the derivation data. The AUC of the simplified rule was 0.71 (95\% CI 0.67 to 0.75 ) in the validation data set. The calibration plot is shown in online supplementary appendix S6; the Hosmer-Lemeshow test for the validation data set yielded a $\mathrm{p}$ value of 0.43 .

\section{Simulation of accuracy in a setting with a lower prevalence of IA}

In contrast to test characteristics, predicted probabilities depend on the prior risk (ie, prevalence) of IA. The frequency of IA among primary care patients with GP-determined clinical suspicion of IA may be different than that observed in EARC. Based on observations in GP practices, ${ }^{5}{ }^{25}$ a simulation was run for the regression and simplified score with a prevalence of inflammatory arthritis set at 20\%. Estimated predicted probabilities for different scores of the multivariable model and simplified rule (in derivation and validation data sets) are presented in figure 2B.

Our simplified rule was implemented in a web application that provides predictions on the presence of current
IA for individual patients; a screenshot is presented in figure 3 . The web application is accessible online at http://caretool.eu/.

\section{DISCUSSION}

GPs play a crucial role in the early identification of RA and often lack confidence in detecting joint synovitis. ${ }^{9}$ In an attempt to solve the contradiction between the need to refer very early and absence of evidence who must be referred, we provided an evidence-based and simple method to identify the presence of IA in patients in whom IA is suspected. This clinical rule helps to select patients to refer for additional investigations (laboratory or imaging) or to secondary care. Hence, the Clinical Arthritis RulE (CARE) could increase appropriateness of healthcare utilisation.

This study is different from studies that derived tools to facilitate triage of patients that have been referred to secondary or tertiary care ${ }^{15-17}$ as our study did not aim to prioritise patients that are already referred. In addition, we aimed to facilitate recognition of IA (as this would necessitate prompt referral to a rheumatologist) and did not perform a longitudinal study to predict development of specific diagnoses (eg, RA) later on. This explains why several factors were found to be associated with presence of IA that are not generally considered typical for RA (male gender, a low number of painful joints, a short symptom duration). GPs generally do well in identifying those at high risk for development of RA (ie, women with subacute smouldering polyarticular, symmetric complaints), and therefore we aimed this tool to assist 


\section{The Clinical Arthritis RulE (CARE)}

\section{Welcome to the Clinical Arthritis RulE (CARE) calculator!}

This calculator estimates the risks of the presence of inflammatory arthritis based on the research of Ten Brinck et al. More information on this calculator can be found at the bottom of the page. The rule is developed for use in patients in whom GPs or other physicians doubt about the presence of inflammatory arthritis. The calculator estimates the risk of the presence of synovitis, detectable at joint examination by experienced rheumatologists.

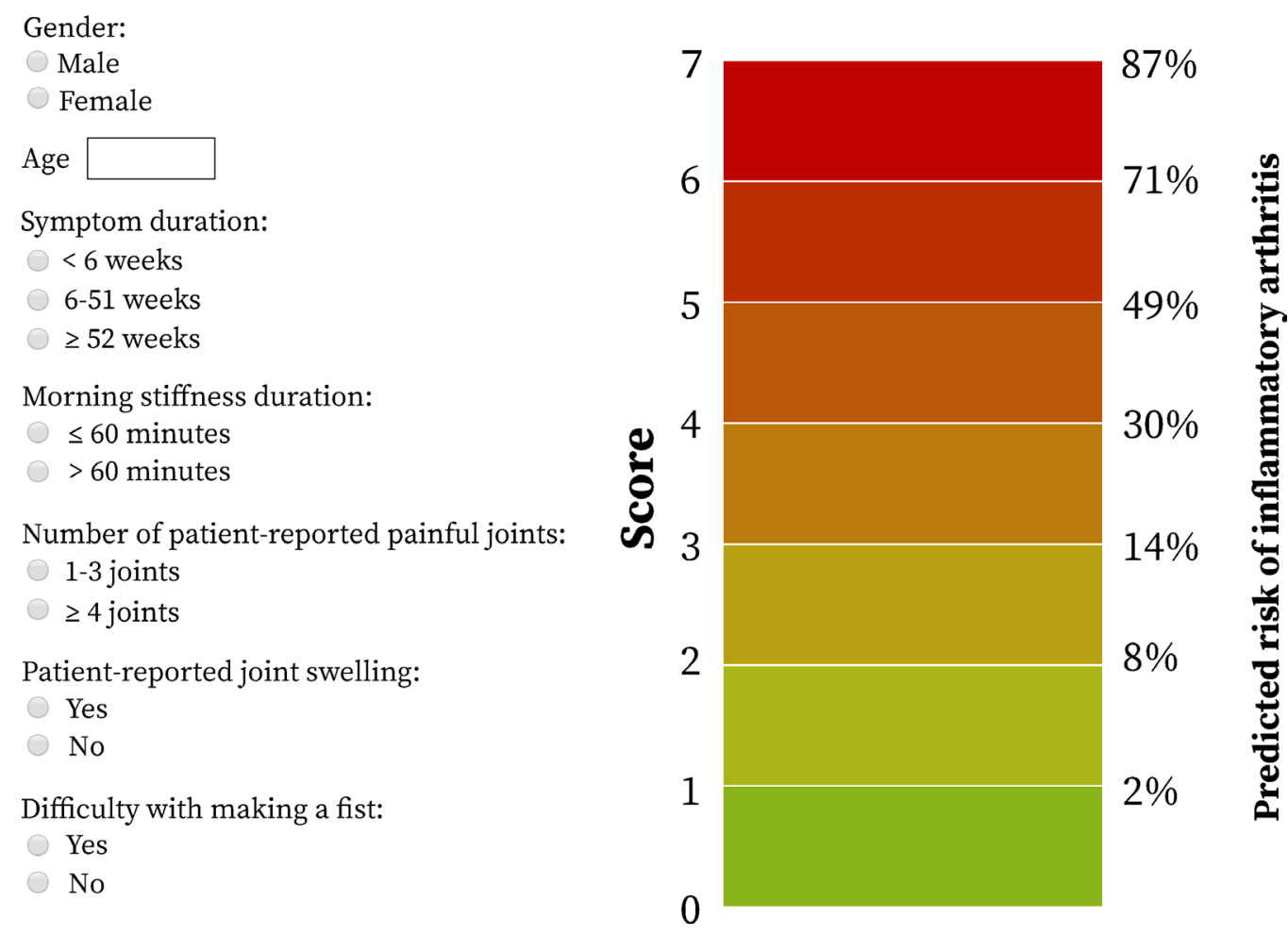

Calculate risk!

This calculator has the option to calculate the risks of current inflammatory arthritis in settings with different pre-test probabilities (i.e. prevalences). The calculator was derived and validated in patients in whom GPs suspected inflammatory arthritis and in whom inflammatory arthritis was confirmed in $41 \%$ of cases. Data obtained in (other) GP practices suggested that the pre-test risk in patient with suspected inflammatory arthritis is approximately $\mathbf{2 0 \%}$. Therefore the calculator can also estimate the risk on inflammatory arthritis in this setting.

Figure 3 A stylised representation of the Clinical Arthritis RulE, to be used in patients in whom general practitioners (GPs) doubt about the presence of inflammatory arthritis. The web application that provides predictions on the predicted risk of inflammatory arthritis for individual patients as can be accessed at http://caretool.eu/.

GPs in decision-making for more atypical or non-classical presentations of IA (eg, due to overlap of symptoms with other diagnoses) leading to doubt. Indeed, many of the patients that did not have synovitis at EARC had symptoms due to diagnoses that are characterised by longstanding or extensive joint pain (eg, osteoarthritis, fibromyalgia), explaining higher scores for a short symptom duration or a low number of symptomatic joints.

Adding other clinical variables might increase the discriminative ability of the model. Potential examples include the squeeze test of the metacarpophalangeal joints (although the diagnostic accuracy was shown to 


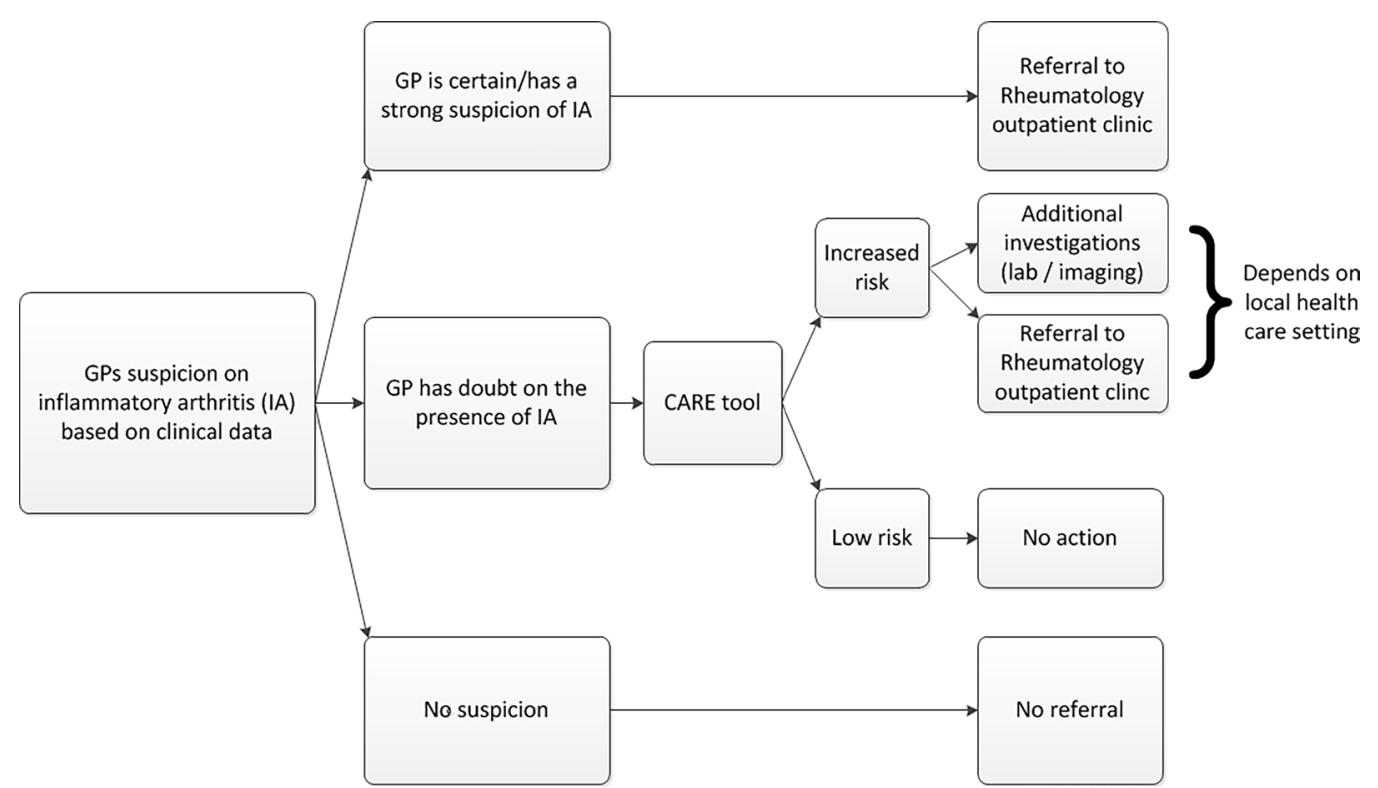

Figure 4 Flowchart of decision-making in patients with suspected early inflammatory arthritis (IA) based on clinical characteristics and the role of the Clinical Arthritis RulE (CARE). GPs, general practitioners.

be only moderate ${ }^{28}$ ), information on family history or functional impairments. These items were not routinely collected before December 2015. Adding data on laboratory investigations to our rule could potentially also increase its discriminative ability. However, our data do not permit us to evaluate this, as additional investigations were done afterwards and only in patients with synovitis at joint examination.

A strength of our EARC for the purpose of this study is that GPs in our region are familiar with the need for early referral and that regional healthcare logistics make rheumatology care rapidly available for patients with arthritis, with $\mathrm{EARC}$ as ultimate service for patients in whom GPs suspect (but are unsure about) IA. With the availability of EARC every week and lack of any waiting list for $\mathrm{EARC}$, we assume a low number of patients not showing up at EARC despite being encouraged by their GP to visit $\mathrm{EARC}$. As $\mathrm{EARC}$ serves as a unique bridge between primary and secondary care, its patients closely resemble the population GPs have contact with and have doubts about. Although EARC is successful in our region, ${ }^{1123}$ this approach may be more difficult to implement in other centres or regions due to a shortage of rheumatologists, or long travelling distances to rheumatology outpatient clinics, and as such a different system is needed to aid GPs in identifying IA. This prompted us to derive a validated rule composed of clinical characteristics that could assist GPs in decision-making for more atypical or non-classical (but nevertheless suspect) presentations of IA, as classical presentations usually do not cause GPs concern.

GPs were discouraged (both by our local communication with GPs and according to national guidelines for GPs) to perform autoantibody testing. ${ }^{29}$ Autoantibody testing in primary care in this region was infrequent, ${ }^{5}$ unlike in other parts of the world. Autoantibody testing may falsely reassure doctors and patients, especially when results are negative, and as such we believe a model based on clinical presentation is more appropriate to facilitate rapid referral.

Another strength is that we studied patients in whom the GPs have indicated a lack of confidence to identify the presence of synovitis. Patients with clinically obvious IA had early access to rheumatological care already. This may enhance the generalisability of the present data to the setting of doubt in primary care. Furthermore, the use of real-life observational data in our study may boost external validity of the results.

A disadvantage of our setting is that the data were not collected in primary care itself, but in a setting intermediary between primary and secondary care. Although musculoskeletal symptoms are a very common reason for consulting primary care, suspected IA is relatively unusual, and the average full-time GP diagnoses only one new patient with RA each year. ${ }^{30}$ Additionally, although $\mathrm{EARC}$ is easily accessible on a weekly basis, the exact number of patients that were referred but did not visit $\mathrm{EARC}$ is unknown. Validation in primary care is required. We studied 'the difficult group' of patients in whom GPs were uncertain of the presence of suspected IA. The prevalence of such patients in primary care may be higher and, as a consequence, the actual prevalence of IA among suspected IA patients may be lower than $41 \%$ in primary care. Since the post-test probabilities strongly depend on the prevalence (ie, pretest probability), a simulation was performed with an estimated prevalence of IA that was half of the prevalence as observed in our data $(20 \%)$. The choice of $20 \%$ was based on the literature from primary care; although not much is known about suspected IA in primary care, two studies suggested a prevalence of IA among suspected patients of $18 \%-27 \% .^{5}{ }^{25}$ We demonstrated the predictive accuracy of the model using a simulated prevalence of $20 \%$. Because of the limitation that 
no other data are available on the prevalence of IA when GPs suspect IA, this estimated prevalence could be an overestimation. However, the observed data could also be an underestimation, as in our setting, GPs were instructed to refer patients with high suspicion/definite arthritis to the regular outpatient clinic. Further external validation in GP settings is therefore required.

GPs in our region are well informed about the importance of the early detection of IA, but the GPs in our region feel that their actual detection skills are not different from that of GPs elsewhere. However, if the detection skills of our GPs are different from that of GPs in other regions, a lower prevalence of IA (and therefore lower pretest probabilities) may be present. As a consequence, the rule may yield lower post-test probabilities. This effect may have been dealt with in the simulation analysis but still external validation in primary care and preferably in different regions or countries is necessary.

We expect that our rule (CARE) might support GPs and other healthcare professionals in the decision-making process in patients with musculoskeletal symptoms in whom they suspect IA, regardless of the region. Of course, the consequences of an increased score will likely depend on the setting and relation with secondary care: it can either influence the decision to directly refer a patient or to first ask for additional laboratory tests (eg, acute phase reactants or autoantibodies; figure 4). A clinical decision aid may be of value to this end as well, as for most laboratory investigations, the diagnostic accuracy depends on the prior risk. Using a simple clinical decision aid first may be more cost-effective than performing additional investigations in all patients in whom there is doubt about IA. Depending on the setting and consequences of a high score, either a sensitive method or a specific method may be preferred; for this reason, cut-offs for both situations are provided. The web application, also easily assessable by phone, facilitates implementation of CARE by GPs, physicians and other healthcare professionals such as physiotherapists in their daily work.

\section{CONCLUSION}

In conclusion, this study developed a clinical rule that supports the identification of patients suspected of having IA by physicians that feel insufficiently experienced in assessment of synovitis by joint examination. We hope the current data are a prelude to a data-driven method that supports GPs, physicians and other healthcare professionals in decision-making in patients with suspected early IA.

\footnotetext{
Author affiliations

${ }^{1}$ Department of Rheumatology, Leiden University Medical Centre, Leiden, The Netherlands

${ }^{2}$ Department of Epidemiology and Statistics, Leiden University Medical Centre, Leiden, The Netherlands

${ }^{3}$ Department of Public Health and Primary Care, Leiden University Medical Centre, Leiden, The Netherlands
}

${ }^{4}$ Research Institute for Primary Care and Health Sciences, Keele University, Newcastle, UK

${ }^{5}$ Haywood Academic Rheumatology Centre, Haywood Hospital, Stoke-on-Trent, Stoke-on-Trent, UK

Acknowledgements We thank the involved patients research partners for their feedback on the questionnaire.

Contributors RMtB, BTvD and AvdHvM designed the study. RMtB, BTvD and SIC conducted the statistical analysis. RMtB, BTvD and AvdHvM conducted the literature search and wrote the article. RMtB, BTvD, HWvS, SIC, MEN, SLH, CM and AvdHvM contributed intellectually to the writing or revising of the manuscript, and approved the final version.

Funding This work was supported by the Dutch Arthritis Foundation and a Vidi grant by the Netherlands Organization of Health Research and Development (RMtB, AvdHvM). CM is funded by the NIHR Collaborations for Leadership in Applied Health Research and Care (CLAHRC) West Midlands, the NIHR SPCR and a NIHR Research Professorship in General Practice (NIHR-RP-2014-04-026).

Disclaimer The funders did not have any role in the study design; the collection, analysis and interpretation of data; the writing of the report; nor the decision to submit the paper for publication. The views and opinions expressed herein are those of the authors and do not necessarily reflect those of the NIHR (UK).

Competing interests None declared.

Patient consent Obtained.

Ethics approval The medical ethical committee of the Leiden University Medical Centre (Commissie Medische Ethiek) approved the study.

Provenance and peer review Not commissioned; externally peer reviewed.

Data sharing statement The calculator presented in this paper is available online at http://caretool.eu. Statistical code and data set are available from RMtB (e-mail; r.m.ten_brinck@lumc.nl) at reasonable request.

Open access This is an open access article distributed in accordance with the Creative Commons Attribution Non Commercial (CC BY-NC 4.0) license, which permits others to distribute, remix, adapt, build upon this work non-commercially, and license their derivative works on different terms, provided the original work is properly cited, appropriate credit is given, any changes made indicated, and the use is non-commercial. See: http://creativecommons.org/licenses/by-nc/4.0/.

\section{REFERENCES}

1. van Nies JA, Krabben A, Schoones JW, et al. What is the evidence for the presence of a therapeutic window of opportunity in rheumatoid arthritis? A systematic literature review. Ann Rheum Dis 2014;73:861-70.

2. Combe B, Landewe R, Daien $\mathrm{Cl}$, et al. 2016 update of the EULAR recommendations for the management of early arthritis. Ann Rheum Dis 2017;76:948-59.

3. NICE quality standard: Rheumatoid arthritis in over 16s [QS33] Quality statement 1: Referral. [Internet] https://www.nice.org.uk/ guidance/qs33/chapter/Quality-statement-1-Referral (accessed on 10 May 2017).

4. Ledingham JM. British Society for Rheumatology National Audit Project. Importance of early detection and referral of rheumatoid arthritis. BMJ 2016;353:i2172

5. Newsum EC, de Waal MW, van Steenbergen HW, et al. How do general practitioners identify inflammatory arthritis? A cohort analysis of Dutch general practitioner electronic medical records. Rheumatology 2016;55:848-53.

6. Emery P, Breedveld FC, Dougados M, et al. Early referral recommendation for newly diagnosed rheumatoid arthritis: evidence based development of a clinical guide. Ann Rheum Dis 2002;61:290-7.

7. Mankia K, Nam J, Emery P. Identifying arthralgia suspicious for progression to rheumatoid arthritis. Ann Rheum Dis 2017;76:e14.

8. National Audit Office. Services for people with rheumatoid arthritis [Internet]. http://www.nao.org.uk/report/services-for-people-withrheumatoid-arthritis/ (accessed on 10 May 2017).

9. Meyfroidt S, Stevens J, De Lepeleire J, et al. A general practice perspective on early rheumatoid arthritis management: A qualitative study from Flanders. Eur J Gen Pract 2015;21:231-7.

10. Raza K, Stack R, Kumar K, et al. Delays in assessment of patients with rheumatoid arthritis: variations across Europe. Ann Rheum Dis 2011;70:1822-5. 
11. van der Linden MP, le Cessie S, Raza K, et al. Long-term impact of delay in assessment of patients with early arthritis. Arthritis Rheum 2010;62:3537-46.

12. Nielen MM, Spronk I, Davids R. Incidentie en prevalentie van gezondheidsproblemen in de Nederlandse huisartsenpraktijk in 2014]. 2017. From: NIVEL Zorgregistratie Eerste Lijn [Internet]. https://www.nivel.nl/nl/NZR/incidenties-en-prevalenties (accessed on 10 May 2017).

13. Jordan KP, Kadam UT, Hayward R, et al. Annual consultation prevalence of regional musculoskeletal problems in primary care: an observational study. BMC Musculoskelet Disord 2010;11:144.

14. Jordan KP, Jöud $A$, Bergknut $C$, et al. International comparisons of the consultation prevalence of musculoskeletal conditions using population-based healthcare data from England and Sweden. Ann Rheum Dis 2014;73:212-8.

15. Bell MJ, Tavares R, Guillemin F, et al. Development of a selfadministered early inflammatory arthritis detection tool. BMC Musculoskelet Disord 2010;11:50.

16. Tavares R, Huang S, Bykerk VP, et al. A parallel group cohort to determine the measurement properties of an early inflammatory arthritis detection tool. Rheumatology 2013;52:2077-85.

17. Villeneuve $\mathrm{E}, \mathrm{Nam} \mathrm{JL}$, Bell MJ, et al. A systematic literature review of strategies promoting early referral and reducing delays in the diagnosis and management of inflammatory arthritis. Ann Rheum Dis 2013;72:13-22.

18. Croydon Health Services NHS Foundation Trust. Early inflammatory arthritis clinic referral form [Internet]. https://www.croydonhealt hservices.nhs.uk/Downloads/GP_resources/Referral\%20and\% 20service\%20information/Arthritis/Primary\%20Care\%20Referral\% 20 form $\% 20$ for\%20Early\%20Inflammatory\%20Arthritis\%20Clinic.pdf (accessed on 10 May 2017)

19. Hampshire Hospitals NHS Foundation Trust. [Internet]. ttps://www. hampshirehospitals.nhs.uk/media/419347/early_arthritis_referral_ additional_information.pdf (accessed on 10 May 2017).
20. Musgrove Park Hospital. Early arthritis referral form [Internet]. http:// www.tsft.nhs.uk/media/353049/early-arthritis-final.pdf (accessed on 10 May 2017).

21. Hülsemann J, Mattussek S, Siegmund-Schultze E, et al. [Early diagnosis of arthritis and spondyloarthritis within the framework of integrated health care in lower saxony]. Z Rheumatol 2006;65:70-4.

22. Guy's and St Thomas' NHS Foundation Trust. ia [Internet]. http:// www.guysandstthomas.nhs.uk/our-services/rheumatology/ specialties/early-arthritis/referrals.aspx\#na (accessed on 10 May 2017).

23. van Nies JA, Brouwer E, van Gaalen FA, et al. Improved early identification of arthritis: evaluating the efficacy of Early Arthritis Recognition Clinics. Ann Rheum Dis 2013;72:1295-301.

24. White IR, Royston P, Wood AM. Multiple imputation using chained equations: Issues and guidance for practice. Stat Med 2011;30:377-99.

25. Knuiman CA, Schers HJ. Het beloop van aspecifieke artritis. Huisarts Wet 2011;54:234-6.

26. King G, Zeng L. Estimating risk and rate levels, ratios and differences in case-control studies. Stat Med 2002;21:1409-27.

27. King G, Zeng L. Inference in case-control studies. Encyclopedia of Biopharmaceutical Statistics 2004 https://gking.harvard.edu/files/ gking/files/1s-enc.pdf

28. van den Bosch WB, Mangnus $L$, Reijnierse $M$, et al. The diagnostic accuracy of the squeeze test to identify arthritis: a cross-sectional cohort study. Ann Rheum Dis 2015;74:1886-9.

29. Janssens $H$, Lagro $H$, Van Peet PG, et al. NHG-Standaard artritis (Eerste versie)]. Huisarts Wet 2009;52:439-53.

30. Symmons D, Turner G, Webb R, et al. The prevalence of rheumatoid arthritis in the United Kingdom: new estimates for a new century. Rheumatology 2002;41:793-800. 